\title{
"humanidades
}

Revista Humanidades

ISSN: 2215-3934

humanidades@ucr.ac.cr

Universidad de Costa Rica

Costa Rica

\section{Tipología del herraje artístico y puerta en Cuzco, Arequipa, La Antigua y Cartagena de Indias como símbolo de estatus social durante el periodo colonial}

Castro Madriz, M. Sc. José María

Tipología del herraje artístico y puerta en Cuzco, Arequipa, La Antigua y Cartagena de Indias como símbolo de estatus social durante el periodo colonial

Revista Humanidades, vol. 11, núm. 2, 2021

Universidad de Costa Rica, Costa Rica

Disponible en: https://www.redalyc.org/articulo.oa?id=498066660005 DOI: https://doi.org/10.15517/h.v11i2.47313

\section{(c) (1) @ $\Theta$}

Esta obra está bajo una Licencia Creative Commons Atribución-NoComercial-SinDerivar 3.0 Internacional. 


\title{
Tipología del herraje artístico y puerta en Cuzco, Arequipa, La Antigua y Cartagena de Indias como símbolo de estatus social durante el periodo colonial
}

\author{
Typology of the Artistic Ironwork and Door in Cuzco, Arequipa, La Antigua and Cartagena de Indias as a Symbol \\ of Social Status During the Colonial Period
}

\author{
M. Sc. José María Castro Madriz \\ Escuela de Artes Plásticas, Universidad de Costa Rica, \\ Costa Rica \\ josemaria.castro@ucr.ac.cr \\ iD https://orcid.org/0000-0001-5562-4214
}

DOI: https://doi.org/10.15517/h.v11i2.47313

Redalyc: https://www.redalyc.org/articulo.oa? $\mathrm{id}=498066660005$

Recepción: 01 Febrero 2021

Aprobación: 17 Marzo 2021

\section{Resumen:}

El presente artículo es el resultado de una investigación de campo realizada en los años 2017 y 2018 en las ciudades de La Antigua, Cartagena de Indias, Cuzco y Arequipa. Como objetivo se plantea el análisis tipológico e iconográfico de las puertas decoradas con herrajes artísticos de influencia española-morisca, así como la subsecuente desvinculación entre lo estrictamente funcional y el valor icónico primigenio. Ahora bien, con respecto a la problemática, se aborda la relación entre la producción y el valor simbólico de los herrajes como objetos de arte utilitario a modo de testimonios materiales del entramado social, político y económico de la sociedad colonial entre el s. XVI e inicios del s. XIX. Asimismo, se destaca la influencia de los gremios organizados y oficializados en herrería dentro del desarrollo de estilos y técnicas de los herrajes coloniales. La metodología se relaciona con la recuperación de la muestra mediante registros fotográficos efectuados en dichas ciudades, así como el análisis iconográfico y la consulta de fuentes escritas históricas. Finalmente, se concluye con una propuesta explicativa que remite a cómo estos objetos funcionales-estéticos perdieron significado de estatus asociado con las clases dominantes para ser elegidos mucho después, por criterios de gusto y tradición, por las clases subalternas.

Palabras ClaVe: colonialismo, tipología, metalurgia, América Latina, sistema social.

\section{Abstract:}

This academic paper is the result of field research carried out during the years 2017 and 2018 in the cities of La Antigua, Cartagena de Indias, Cuzco and Arequipa. Its objective is to analyze from a typological and iconographic perspective the doors decorated with artistic ironworks of Spanish-Moorish influence, as well as the subsequent disconnection between the strictly functional and the original iconic value. The fundamental problem of analysis is the relation between production and symbolic value of ironworks are identified as objects of utilitarian art, as material testimonies of the social, political and economic framework of colonial society between the c. XVI and early c. XIX. The influence of organized and officialized guilds in blacksmithing in the style and technical development of colonial ironworks is also highlighted. Through the photographic record made in the four cities, the iconographic analysis and the consultation of historical written sources; an explanatory proposal is presented as a main conclusion by which these functional-aesthetic objects lost meaning of status associated with dominant classes to be chosen much later by criteria of taste and tradition by subaltern classes.

KEYWORDS: colonialism, typology, metallurgy, Latin America, social systems.

\section{INTRODUCCIÓN}

La problemática que da origen a esta investigación está relacionada con la perspectiva ontológica clasificatoria del objeto. Los herrajes artísticos de forja y fundición no son considerados arte, puesto que carecen de espacios o actores validadores (galerías y museos), o bien del reconocimiento académico científico (historia del arte, crítica, estudios estéticos especializados). A pesar de ello, no debe ignorarse el hecho de que se emplean gran 
variedad de procedimientos artísticos para elaborar los herrajes, tales como el dibujo, el modelado, el diseño y la escultura.

Así, resulta oportuno traer a colación la división producida en el Renacimiento, en la cual se sostenía una distinción entre las artes mayores, o cultas (liberales), y las artes menores (mecánicas). Las artes menores, usualmente, estaban relacionadas con los trabajos manuales de gremios organizados, según lo señala Tessier (2016): "En la Europa del siglo XVI se pretendía distinguir las artes mecánicas de las artes liberales gracias al surgimiento de las academias de artistas que reúnen la élite de una profesión prestigiosa de intelectuales” (p. 28). Además de esto, la ausencia de análisis de productos materiales coloniales de este tipo (artes menores) evidencia el dominante enfoque de la histórica del arte contemporáneo.

Ahora bien, hay que tomar en consideración que los herrajes virreinales de las puertas de las ciudades coloniales son abundantes tanto en sus formas como en sus motivos. Además de esto, no existen registros históricos específicos sobre estos objetos, pues, en el caso de la arquitectura religiosa católica, forman parte de un todo. De esta manera, dichos objetos cumplían funciones de ornamentación para las construcciones habitacionales y, en muchos casos, dependiendo del herraje, solamente eran fabricados con objetivos funcionales. El encargo de herrajes era básicamente una actividad privada comercial entre el taller (o artesano) y los contratantes. Era esperable que muchos de esos talleres no llevaran registros de producción, o al menos, en esta investigación no se han encontrado. Por lo anterior, lo único que queda como material de estudio es aquello que no fue destruido por los eventos naturales, fundido para reutilización del metal o vendido como pieza de anticuario, ya que se comprobó, en las cuatro ciudades estudiadas, la venta libre de herrajes originales porque no son protegidos como patrimonio cultural.

Aunado a lo anterior, los herrajes artísticos de forja y fundición en puertas coloniales de América Latina son objetos poco estudiados. De la misma manera, son analizados escasamente por la historia del arte en la Colonia, la cual se centraba, de manera fundamental y tradicional, en la imaginería pictórica, escultórica y la arquitectura. Además, son objetos de estudio prácticamente ausentes dentro de los análisis de material histórico de las tempranas repúblicas emancipadas del mundo colonial español. Desde la historia tradicional, narrativa y lineal, los objetos detentan valor tangencial a los actores, procesos y documentos históricos (fuentes). En este sentido, es relativamente reciente el cambio de paradigmas históricos dentro de la disciplina que permiten la existencia de otras historias y significados posibles, como lo plantea Koselleck (2004), quien explica la mutabilidad de los conceptos en relación con la realidad fáctica. En este sentido, los herrajes artísticos de forja y fundición en puertas coloniales de América Latina son objetos producidos conceptualmente por seres humanos que responden a un tiempo y a un esquema de valor: simbólicoconcepto-funcional.

Por todo lo anterior, es necesario abordar el tema desde un enfoque intermedio, relacionado con la variable de análisis instrumental denominada Historia de los objetos. Desde este enfoque, estos objetos son entendidos como actantes o testimonios materiales no humanos del pasado. De esta manera, gracias a ellos y su valor funcional y simbólico, es posible obtener conocimiento tanto del sistema social de las colonias españolas en América como de las tendencias estéticas del periodo. En suma, desde este enfoque intermedio, se comprenden "los objetos como un documento de análisis (...) entenderlos dentro de las redes de abstracciones y prácticas que todo conjunto social va creando y cambiando continuamente” (Ruiz, 2005, p. 5). Así, es conveniente analizar el origen y la forma de especialización de este tipo de producciones materiales, estudiarlas como resultado de una formación profesional, resguardada e impartida a los aprendices, a través de gremios conformados por artesanos independientes, muchos de los cuales quedaron en el anonimato.

A partir de lo explicado, las preguntas que motivan este estudio son ¿por qué no todas las ciudades fundadas por los conquistadores y colonizadores españoles poseen herrajes en sus puertas?, ¿será posible encontrar parámetros comunes y diferenciadores en los herrajes para puertas, presentes en las cuatro ciudades estudiadas, que aporte algún conocimiento en cuanto al uso de estos en las clases dominantes de la sociedad 
colonial?, ¿es posible generar una tipología que permita clasificar los herrajes de puerta para el estudio iconológico e iconográfico desde la perspectiva de una historia de los objetos?

El objetivo de esta investigación cualitativa es plantear una tipología que permita tanto el estudio como la clasificación de todos estos objetos para su catalogación temática. Esta organización se haría de acuerdo con tres elementos: en primer lugar, los criterios estéticos de la producción, es decir, las influencias artísticas de representación; en segundo lugar, la técnica ya existente en el periodo histórico específico; y, en tercer lugar, el motivo o el destino funcional de diseño de estos objetos, los cuales están ligados a la necesidad de reconocimiento dentro de la sociedad colonial en términos de posesión.

Ahora bien, la muestra de estudio se limita a cuatro ciudades: Cuzco, Arequipa, La Antigua, Guatemala, y la ciudad de Cartagena de Indias. En dichas localidades aún quedan en pie casas virreinales, "cuando hablamos de viviendas virreinales, nos referimos sobre todo a las tipologías de casas grandes o casonas" (Velasco, 2016, p. 82). El estudio de campo para recolectar el material fotográfico se efectuó a pie en una extensión aproximada de diez cuadras en la periferia de la Plaza Central que, bajo los esquemas españoles, está siempre acompañada por la iglesia mayor (usualmente catedral). A partir de ese punto se recorren los bloques o cuadras desde la periferia hasta el centro. La razón de que ese trayecto sea así es para incluir el centro histórico de las cuatro ciudades que, usualmente, presenta una mayor conservación arquitectónica con relación al área que circunda estos centros.

Respecto de la herramienta metodológica, se utilizó la recopilación de más de cuatrocientas fotografías clasificadas por estilo y por ciudad, para agruparlas en apartados temáticos, los cuales constituyen la propuesta tipológica de este estudio. Además, se eligieron cuarenta y nueve de estas como muestras principales. Se elaboró una ilustración lineal y dos tablas, las cuales permiten explicar claramente las principales características de las variables tipológicas de herrajes para puerta en forma de figuras compuestas numeradas del uno al doce, sin obviar que dentro de cada categoría se presentan tantas variables como objetos y creadores existen.

Mediante criterios aportados por la investigación de los textos especializados, se efectuó la clasificación de estilos. Dichos estilos están conceptualmente relacionados entre sí por un eje transversal investigativo referido a la vida y a la estructura social durante la Colonia. Esta clasificación relaciona al objeto material con el concepto de estatus y de posesión de las clases dominantes coloniales en América, como lo explica la historiadora Ruiz (2005) al afirmar que "existe, en este sentido, una relación personal e individual con lo material, en la cual cada sujeto organiza y proyecta su vida según la posesión efectiva de los bienes que considera importantes" (p. 6).

Como variable independiente se identifica la morfología propia de los herrajes y como variable dependiente se considera el valor simbólico material del objeto. Ambas variables implementadas en el análisis de fuentes históricas desde la perspectiva de la historia de los objetos. De igual manera, el enfoque metodológico pretende analizar las diferencias técnicas entre la forja y la fundición colonial antigua, así como determinar los factores históricos que propiciaron el surgimiento, el desarrollo y la evolución de los gremios productores de herrajes artísticos ${ }^{1}$.

\section{ANTECEDENTES HISTÓRICOS, GREMIOS ORGANIZADOS PARA LA ELABORACIÓN DE HERRAJES EN FORJA Y FUNDICIÓN EN PUERTAS COLONIALES}

Con respecto a los herrajes coloniales en América, es oportuno citar algunos antecedentes históricos, así como técnicos de la metalurgia antigua. Esto, con el fin de entender de qué forma las técnicas traídas desde Europa, principalmente aquellas relacionadas con el establecimiento supervisado de herreros españoles, incidieron dentro de la producción colonial autóctona de herrajes. Cabe mencionar que estos inmigrantes llegaron a América en busca de la riqueza de las recientes minas de metal noble, de las cuales buscaban extraer gran 
cantidad de materia prima. No obstante, debido a la escasez de recursos, acabaron dedicándose a la forja de metal ferroso.

En cuanto a la división del trabajo, el aporte técnico de los herreros nativos fue valorado con reservas, "los españoles reconocen únicamente la calidad de factura, considerándolas no como obras de arte sino como obrajes artesanales" (Tessier, 2016, p. 28). Por su parte, los mestizos fueron valorados por la autoridad virreinal, hasta el punto de que se les prohibió el abandono de las ciudades por causa de su buen trabajo.

El cristianismo europeo, importado al Nuevo Mundo con el objetivo de consolidar el proceso de conquistaevangelización, también trajo parámetros estéticos y técnicos con relación a la elaboración de herrajes para iglesias, así como costumbres o rituales relacionados con el concepto de puerta sagrada. En este sentido, la puerta sagrada era usada tanto como elemento ceremonial litúrgico como para "la misericordiosa acogida al penitente o pecador" (Uribe, 2007, p. 458). Este segundo uso tenía que ver con la implementación del derecho de asilo para perseguidos políticos, militares sublevados o sediciosos, mujeres presuntamente adúlteras o fornicadoras, asesinos accidentales y criminales menores como ladrones y estafadores. Estas personas podían utilizar el recurso desesperado del grito y la súplica ad portas de A iglesia me llamo, tradición colonial peruana que consistía en golpear los llamadores de las iglesias para buscar refugio del castigo de la autoridad legal.

Finalmente, las piezas que se analizarán en este estudio, en su mayoría, son del siglo XVIII hasta las primeras tres décadas del siglo XIX, identificado como el temprano periodo republicano.

\subsection{Los Herrajes, LA CONQUista y LA COLONIA: CONFORMACión DE NUEvos GRemios}

Domínguez (1987) considera que es difícil hablar de gremios sin entender también la figura de las cofradías (muchas veces dedicadas a un santo patrón o virgen): "ambas instituciones aparecían en la edad media española formando una sola corporación que agrupaba a los artesanos de un mismo oficio y se ocupaba a la vez de los aspectos religiosos, caritativos y mutualistas propios de la cofradía” (p. 79).

Para la sociedad noble española de los siglos XVI y XVII, el trabajo manual era innoble. La guerra y las letras se tenían por los únicos trabajos propios del hidalgo, según firmísima tradición española ${ }^{2}$ y como, de manera clara, afirman Durand et al. (1992): "El desprecio castellano por el comercio y los oficios humildes, confiados ordinariamente a moros y judíos, es rasgo fundamental del ser hispánico” (p. 45). Como se podrá notar en la cita, estos trabajos manuales se destinaban a las clases sociales consideradas más bajas. De igual manera, los únicos trabajos propios del hidalgo eran intelectuales o bélicos, aunque resulta importante señalar que conquistadores como Francisco Pizarro ejercieron oficios manuales, según lo evidencian las crónicas de conquista: "Gustaba de atender su huerto y vigilaba en persona sus casas de campo" (Durand et al., 1992, p. 57). Aunado a lo anterior, se debe señalar que, para los conquistadores españoles, el trabajo manual y el comercio eran actividades acaparadas por sus descendientes directos y, posteriormente, por el resto de la sociedad colonial, en específico, para el trabajo con hierro. Es hasta "la primera mitad del siglo XVI que aparecerá legalmente el gremio de los herreros y cerrajeros" (Muro, 1956, p. 338).

Las crónicas de la época consignan que los indígenas cercanos a los españoles fueron quienes aprendieron las técnicas de forja con notable celeridad. Por ejemplo, Carrasco (1991) afirma que "la mayor incorporación de técnicas europeas a la vida indígena estuvo limitada a los grupos urbanos más allegados a los españoles" (p. 18). Además, en algunas de estas crónicas se expone que los indígenas detentaban una larga tradición con respecto al manejo del oro y del cobre -como bien lo afirma Lechtman (2007) en The Inka and the Andean Metallurgical Tradition-. De igual manera, se narra acerca de la existencia de cierta originalidad dentro de las creaciones indígenas. Esto quiere decir que ellos incorporaban patrones de estilo personales, así como el previo conocimiento cultural: "labrar plata y oro muy primamente" (Tessier, 2016, p. 27). Todo esto era factible a causa del auspicio, la formación y la inspección de los frailes. Dentro de esta enseñanza y, al margen de las disposiciones de las ordenanzas, se utilizaba y se capacitaba a los indígenas para la elaboración de clavos, 
cerraduras, rejas, llamadores y otras piezas para los monasterios e iglesias, según lo señalan los Memoriales de Fray Toribio de Motolinía (c. 1482-1569) en su Libro de Oro (Sobrino, 1997). Con respecto al dominio militar español, existía "la elaboración de grilletes para los prisioneros y las infames barras para marcar a rojo vivo a los esclavos” (García, 1966, p. 11).

Por esta razón, no resultó extraño el hecho de que el 15 de marzo de 1524, siete días después de constituirse el primer cabildo, conformado por "los oficiales de república que tenían los títulos de alcalde y de regidor" (Carrasco, 1991, p. 12), la primera ordenanza dictada por Hernán Cortés consolidara al gremio de los herreros como el de mayor relevancia para la conquista (Cox, 1966, p. 104). Posteriormente, las ordenanzas de la Nueva España de 1568, derivadas de las homónimas de los cerrajeros sevillanos de 1502, describen los exámenes que deben presentar quienes deseen convertirse en maestros herreros, así como el estricto ejercicio del oficio y las garantías de trabajo bajo pena de multas, prisión y pérdida del oficio en caso de infracción (García, 1966, p. 12). En algunos sumarios las multas eran castigos físicos ${ }^{3}$, por ejemplo, en Guatemala "se condenaba al infractor reincidente cien azotes" (Domínguez, 1987, p. 103).

El reconocimiento inicial de los oficios, así como la consiguiente conformación de los futuros gremios coloniales, inicia con las ordenanzas, por ejemplo, la de Cuzco de 1572 que, bajo el título De los oficios mecánicos, establece arancel y licencia de tienda para los herreros (Domínguez, 1987, p. 87). Las ordenanzas varían en contenido y en forma entre colonias. Además, no se puede establecer uniformidad entre ellas. A pesar de ello, en todas se identifican y se reconocen las actividades relacionadas con la forja de metal, en las categorías de cinco maestros artesanos principales: herreros, paileros, cerrajeros, herradores y espaderos. Estas categorías están organizadas en gremios y se localizan en mercados, en los que "los funcionarios del cabildo estaban encargados de recoger y entregar el tributo, de reglamentar el funcionamiento de los mercados locales" (Carrasco, 1991, p. 13). Los mercados eran vistos con desaire, desde la perspectiva de algunos criollos, como el noble Carlos Gómez, quien en una carta al Rey dice: "Está claro que dineros se hallan en poder de mercaderes y tratantes, que no en gente ciudadana y noble" (Durand et al., 1992, p. 45).

Siguiendo con lo anterior, estos gremios estaban organizados por maestros, oficiales y aprendices. La agrupación de los maestros era una cúpula de dirigentes que vigilaba la práctica del oficio y que recibía denuncias de trabajos clandestinos. Estaban ubicados en calles específicas, las cuales, con el paso del tiempo, adoptarían los nombres del oficio principal. La necesidad de satisfacer la demanda de objetos artesanales para la vida colonial es reconocida desde el trono español "cuando Carlos III decide rehabilitar la dignidad de los oficios manuales, alarmado por la situación financiera del país, algunas autoridades locales coloniales consideran necesario justificar la aceptación de esos trabajos entre los usos del hidalgo" (Durand et al., 1992, p. 57).

Las cartas de examen, por su parte, eran emitidas por los cabildos y suscritas por escribanos reales de las ciudades que las emitían (Nieto, 2018, p. 175). Eran cartas que certificaban a los nuevos maestros de oficios, describían el lugar de nacimiento, su edad, rasgos étnicos y origen (en caso de migración). En suma, certificaban al artesano como miembro de un gremio con derechos y obligaciones. Cabe destacar que este registro era solamente para varones libres, lo que quiere decir que se excluían los datos relacionados con las mujeres, los mestizos, los mulatos y los esclavos negros.

Según Konetzke (1949), se presentaron, en todos los gremios, prohibiciones tanto para el ingreso a los gremios como para el derecho a tiendas públicas. A pesar de ello, ante la presión de los dueños de esclavos por la gran demanda de herreros, se permitió que los herreros se ocuparan de encargos oficiales. No obstante, es lógico esperar que el reconocimiento de maestro no fuera concedido nunca de manera oficial (p. 72). Como medida de protección hacia los gremios locales, los cabildos regularon las tasas de aranceles a los productos de herrería de colonias vecinas ${ }^{4}$, por ejemplo, entre México y Guatemala.

No en todas las colonias la extracción de metales era considerable como sí se constata en las cartas de Cortés de 1524 al referirse a Nueva España. Pese a eso, la creciente demanda de objetos de forja en las colonias originó que los precios de productos elaborados en ese metal se encarecieran, hasta el punto de ser prohibitivos. 
Por ello, se importaron desde España gran cantidad de utensilios y herrajes que aún siguen en las catedrales de México, Perú y otros lugares. Finalmente, hubo una emigración de herreros españoles en el siglo XVII (García, 1966, p. 11).

Con el paso del tiempo, hasta los primeros años del siglo XIX, los herreros, así como otros artesanos que eran considerados profesionales, bajo carta de examen emitida por el cabildo, dejaron de guardar las ordenanzas de sus gremios y, con las pugnas internas para la elección de líderes, cayeron en la categoría de "letra muerta todas las regulaciones coloniales tempranas" (Muro, 1956, p. 345). Esto dejó a la regulación de la oferta y la demanda las políticas de precio así como las de asociación gremial. Por ello, los agonizantes gremios piden a la Corona española adherirse a los gremios peninsulares, en una medida desesperada por mantener el sistema regulatorio de herreros novohispanos.

\subsection{Relación DE LOS HERRAJES Y LAS ClASES DOMINANTES DURANTE LA Colonia Como SÍMBOLO DE ESTATUS}

Específicamente sobre la relación entre herraje y estatus social, el autor y estudioso de los herrajes del Perú, Rainer Hostnig (2010), dedica un capítulo completo de su tesis doctoral a los herrajes de puerta y, con respecto al tema, señala "cómo en la Europa medieval, también en América Latina el modelo y la carga ornamental del aldabón reflejaban el estatus y la economía de los que habitaban detrás de las puertas o portones o quiénes eran propietarios del edificio" (p. 6). El autor resalta algunos dichos antiguos españoles como tener buenas aldabas o a tal casa, tal aldaba, los cuales expresan esta idea precisamente.

Hostnig (2010) fundamenta la relación de valor económico elevado del herraje de puerta gracias a los registros del protocolo de Juan Cornejo en 1954, en los que compila y ordena documentos comerciales de transacciones coloniales en Cuzco del siglo XVII, las cuales poseían un nivel de legalidad notarial. De ellas, se rescatan los dos siguientes fragmentos de 1700 y 1702, respectivamente: "Pedro Fernández de Oquendo, se obliga a entregar al capitán Alonzo de Aguilar, 400 clavos de bronce con sus espigas de fierro, a modo de una flor de seis hojas, pagándose por cada clavo a razón de un peso" y "Joseph Sina, se compromete para hacer y entregar a doña Luisa de Castillo (...), 110 clavos de cobre, de la hechura y tamaño de los de la casa del capitán don Santiago de Sumalave, a razón de 5 reales y medio" (Cornejo, 1958, citado por Hostnig, 2010, p. 6). Así, el costo de 400 pesos y 5 reales y medio (reales de 8) es de consideración para el sistema de salarios de la Colonia. Para tener un factor de referencia, tómese en cuenta lo siguiente: un indígena tejedor, según la ordenanza de Velazco de 1597 (virreinato del Perú) ganaría, en todo un año, 42 pesos más la comida, que consistía en unas "15 libras de carne y un poco de sal" (Salas, 2004, p. 91). Con la distancia del caso, en incremento salarial, entre el siglo XVI y XVIII, era prácticamente imposible para las clases subalternas coloniales acceder, primero, a herrajes y, por supuesto, en segundo lugar, a la puerta y la propiedad colonial de tipo señorial.

En la sociedad colonial existía “una marcada necesidad de 'exteriorizar' el posible status de la persona, familia o institución” (Ruiz, 2005, p.7), con el objetivo de reforzar públicamente un sistema de ordenamiento y de consumo. Este ordenamiento estaba basado en un sistema jerárquico, como lo destaca Ruiz (2005): "Es una sociedad en donde lo visual y lo gestual tienen un peso decisivo en la estructuración de las representaciones mentales de las jerarquías y los roles" (p. 8). Con relación a la función simbólica del objeto como elemento de distinción social, se debe comprender que "hay objetos que reconocen una clase social, sobre todo en lo que afecta a su valor de intercambio, cuanto más caro más difícil de obtener, y, por lo tanto, indica un alto estatus social" (Carreras y Nadal, 2002, p. 69). Todo esto quiere decir que, a través de los objetos, se puede obtener información específica acerca de la cultura que los produce.

Los herrajes para puerta cumplen con la función de demostrar el poderío adquisitivo de la familia que, en muchos casos, debido a sus portales, se equiparaban a los poderes militares, políticos y religiosos, al simular lo profuso de la ornamentación de puertas de palacios e iglesias, ya que "en herrería de puertas encontramos 
muchos elementos comunes con las casas y palacios" (De Amesti, 1982, p. 72). Por ejemplo, en Cuzco se encuentran antiguas puertas de casas señoriales con un promedio de 80 a 120 clavos de forja con bula, sin contar los aldabones de proporciones muy similares al de las iglesias. Muchas de estas casas fueron propiedad de criollos notables socialmente y que, en su mayoría, eran "comerciantes urbanos por origen y vocación que se convierten en terratenientes y hacendados-exportadores" (Palacios, 1980, p. 1669).

El precio de los herrajes los hace depositarios de un alto valor simbólico en el mundo colonial y, al mismo tiempo, en cierta medida, este costo representa los valores utópicos de un nuevo mundo abierto a la riqueza. En suma, "los objetos son elementos descriptores de una sociedad y de un individuo" (Carreras y Nadal, 2002, p. 67). El valor de las pertenencias materiales, en buena medida, es el resultado de una construcción como grupo en la cual el objeto se sitúa en una escala de valor. Al respecto, los autores Carreras y Nadal (2002) detallan y diferencian entre dos calidades: una "social y otra individual" (p. 68).

Otro concepto relevante también es el de cultura material. Este concepto revela la estructura de consumo de la sociedad y, a partir de ello, se puede intuir que, ante tendencias de consumo de objetos y servicios que no son de primera necesidad, tales como la vestimenta y la alimentación, la "cultura material puede ser el punto de partida para nuevos modos de comprensión de la sociedad, como la economía y el consumo, el espacio privado o doméstico, la historia de los hábitos y costumbres" (Ruiz, 2005, p. 6). De esta manera, se está ante clases dominantes con el poder adquisitivo suficiente para detentar objetos suntuosos. Mucha de esa riqueza estuvo contenida en la propia geografía, elegida para la fundación y el desarrollo de las ciudades coloniales. Para ilustrar esta idea, tómese en consideración la cantidad de yacimientos de metales que queda registrada en La Crónica del Perú de Cieza (2005) (crónica original terminada en 1550), la cual dice: "Hay gran cantidad de cobre, y mayor de hierro por los secadales y cabezadas de las sierras que abajan a los llanos. En fin, se halla plomo, y de todos los metales que Dios crió [sic]" (p. 282).

Por las razones anteriores, se puede afirmar que el costo de los herrajes era alto y que las clases subalternas no accedían a estos en una primera etapa. Asimismo, se puede afirmar también que los criollos, al adquirir riqueza mediante el comercio, obtenían más propiedades y en ellas construyeron casas señoriales. Finalmente, que la estética de sus puertas es el resultado de la imitación de portales de instituciones de poder como la Iglesia y lo político-militar.

\section{Aproximación tipológica a los herrajes de PUERTA}

Contreras (1984) aclara varios términos arqueológicos relevantes, por ejemplo, atributo: "rasgo reconocible, una variación independiente de cualquiera de los elementos que componen un artefacto"; tipo: "grupo de objetos similares (enfoque de agrupamiento de ítems)"; y, finalmente, tipología: "sistema de clasificación basado en los atributos, tales como la forma, la manufactura o la funcionalidad de los artefactos. Los miembros representativos de este sistema son conocidos como serie de tipos" (p. 328).

Tschauner (1985) hace referencia al esquema de enfoque tradicional de A. Krieger (1944) en su estudio sobre la pertinencia del modelo tipológico como herramienta u obstáculo: "El tipo es esencialmente una combinación específica y coherente de rasgos". Asimismo, "el tipo no es un conjunto de artefactos reunidos en un grupo por una clasificación, sino la categoría mental con base a la cual se forma el grupo de artefactos" (Tschauner, 1985, p. 40). Es importante rescatar, del pensamiento de Krieger, que el tipo se entiende como esquema mental necesario para el estudio, la comparación y la definición de unidades culturales, así como la facilidad comunicativa entre personas investigadoras.

Desde esta perspectiva, tipología no es lo mismo que clasificación simple, pues la primera estructura y analiza la muestra, según un parámetro o un esquema mental previo. Lo anterior implica un razonamiento profundo de las formas del objeto, valor estético y simbólico dentro de la cultura material. Por otra parte, desde la perspectiva taxonómica, el denominado 'sistema tipo-variedad', según Tschauner (1985), “está 
ideado para crear unidades taxonómicas comparables que faciliten la comparación de materiales de diferentes sitios” (p. 41).

Aunque los virreinatos mantenían ciertas similitudes impuestas por los conquistadores españoles, eran muy diversos en sus producciones materiales y "culturas materiales" (Moreyra, 2012). En el caso específico de las bulas y los llamadores de puerta no se puede saber con certeza el año de producción de cada una, porque solo se refiere el año de finalización de la construcción de las instaladas en puertas de iglesias. Lo que sí se puede determinar es su condición de réplica o de pieza original de fundición/forja, por medio de la examinación de las marcas de molde, la intervención de herramientas, o los rastros de rebabas -remanentes de metal no deseados en bordes del objeto- y las deformaciones de moldes de arena usados para duplicar de manera posterior los originales.

El concepto de variedad del sistema, citado anteriormente, resulta útil en la construcción de una tipología específica de los herrajes, ya que "una variedad difiere del tipo al que está relacionada en una o más particularidades” (Wheat et al., 1958, p. 35). Se ha citado anteriormente a Irving B. Rouse con su aporte al concepto de tipo de Krieger, sin embargo, vale la pena resaltar su aporte con relación a la clasificación analítica, que dice: "Cualquier estándar, concepto o costumbre que rige el comportamiento de los artesanos de una comunidad, que pasan de generación en generación y que se puede difundir de comunidad en comunidad sobre distancias considerables" (Rouse, 1960, citado en Tschauner, 1985, p. 43).

Hasta este punto, se poseen algunos elementos sólidos con los que se construirá un método variable múltiple. A partir de ello, se construye, identifica y, posteriormente, se agrupan los herrajes que constituyen el corpus de la muestra seleccionada.

A continuación, se presenta un esquema conceptual (véase Tabla 1) y se explican los tipos, para la construcción de una tipología de los herrajes para puertas de las cuatro ciudades estudiadas en el periodo colonial con base en sus remanentes materiales en materia de puertas. En cada apartado se presentan figuras compuestas por diversas fotos que describen visualmente las particularidades de cada tipo. 
TABLA 1

Esquema tipológico de herrajes coloniales y puertas

\begin{tabular}{|c|c|c|c|c|c|}
\hline Tipo & Variables & Téc & nica & Iconografia & Descriptor \\
\hline \multirow[b]{2}{*}{ Portones } & $\begin{array}{l}\text { Iglesia o } \\
\text { catedral }\end{array}$ & \multirow{3}{*}{\multicolumn{2}{|c|}{$\begin{array}{l}\text { Bastidor tipo } \\
\text { cuadros } \\
\text { (travesaños } \\
\text { verticales y } \\
\text { horizontales) }\end{array}$}} & Religioso & $\begin{array}{l}\text { Uno o dos } \\
\text { portillos, dos } \\
\text { hojas y remate } \\
\text { de arco ojival o } \\
\text { medio punto }\end{array}$ \\
\hline & Señorial & & & $\begin{array}{l}\text { Religioso / } \\
\text { secular }\end{array}$ & $\begin{array}{l}\text { Un portillo, } \\
\text { recargado de } \\
\text { herrajes / } \\
\text { bastidores de } \\
\text { cuadros o } \\
\text { marco }\end{array}$ \\
\hline Puertas & $\begin{array}{l}\text { Colonial } \\
\text { simple }\end{array}$ & & & Secular & $\begin{array}{c}\text { Menor tamaño I } \\
\text { bisagras, rejillas } \\
\text { y herrajes } \\
\text { varios }\end{array}$ \\
\hline \multirow[b]{2}{*}{ Aldaba } & $\begin{array}{c}\text { Cabeza } \\
\text { zoomorfa }\end{array}$ & \multirow{2}{*}{\multicolumn{2}{|c|}{ Fundición hierro / bronce }} & $\begin{array}{l}\text { 1. Perro } \\
\text { 2. Mono } \\
\end{array}$ & $\begin{array}{c}\text { Estilización del } \\
\text { animal } \\
\end{array}$ \\
\hline & $\begin{array}{c}\text { Cabeza } \\
\text { antropomorfa }\end{array}$ & & & $\begin{array}{l}\text { 1. Grotesca } \\
\text { 2. India } \\
\text { 3. Virgen }\end{array}$ & $\begin{array}{l}\text { Estilización del } \\
\text { arquetipo }\end{array}$ \\
\hline \multirow[b]{2}{*}{ Aldabón } & $\begin{array}{c}\text { Cabeza } \\
\text { zoomorfa }\end{array}$ & & & $\begin{array}{l}\text { 1. Perro } \\
\text { 2. Mono }\end{array}$ & \multirow{2}{*}{$\begin{array}{l}\text { Mayor tamaño } \\
\text { que aldaba, } \\
\text { usualmente en } \\
\text { pares, ubicadas } \\
\text { a mayor altura }\end{array}$} \\
\hline & $\begin{array}{c}\text { Cabeza } \\
\text { antropomorfa }\end{array}$ & Fundición hi & arro / bronce & $\begin{array}{l}\text { 1. Grotesca } \\
\text { 2. India } \\
\text { 3. Virgen }\end{array}$ & \\
\hline \multirow{4}{*}{$\begin{array}{c}\text { Argollas de } \\
\text { forja }\end{array}$} & Cuña & Forja c & talana & \multirow{3}{*}{ No figurativa } & $\begin{array}{c}\text { Espiga para } \\
\text { muro }\end{array}$ \\
\hline & Retorcida & Retorcid & en forja & & \\
\hline & $\begin{array}{l}\text { Simple } \\
\text { redonda }\end{array}$ & Forja m & artillada & & Para puerta \\
\hline & Para caballo & Forja y lim & do en frío & Figurativa & $\begin{array}{l}\text { Abierta para } \\
\text { muro }\end{array}$ \\
\hline \multirow{5}{*}{$\begin{array}{l}\text { Bula de } \\
\text { clavo }\end{array}$} & Festonado & Fundiciór & de arena & No figurativa & \multirow{5}{*}{$\begin{array}{l}\text { Fijación de } \\
\text { tablones y } \\
\text { decoración } \\
\text { exterior }\end{array}$} \\
\hline & Labrado & Fundido y la & rado en frío & Geométrica & \\
\hline & $\begin{array}{c}\text { Floral } \\
\text { Chupón }\end{array}$ & \multicolumn{2}{|c|}{ Fundición cera perdida } & $\frac{\text { Figurativa }}{\text { No figurativa }}$ & \\
\hline & $\begin{array}{l}\text { Labrado } \\
\text { calado }\end{array}$ & $\begin{array}{r}\text { Fundido, lab } \\
\text { en }\end{array}$ & $\begin{array}{l}\text { ado y calado } \\
\text { río }\end{array}$ & Geométrica & \\
\hline & Marino & $\begin{array}{r}\text { Fundición } \\
\text { per }\end{array}$ & $\begin{array}{l}\text { ena / cera } \\
\text { da }\end{array}$ & $\begin{array}{l}\text { Estrellas de } \\
\text { mar, } \\
\text { caracoles }\end{array}$ & \\
\hline \multirow[t]{2}{*}{ Llaves } & \begin{tabular}{|c|} 
Portón \\
Puerta \\
Candado \\
\end{tabular} & Fundida & labrada & \multirow[t]{2}{*}{ No figurativa } & \multirow{2}{*}{$\begin{array}{l}\text { Seguridad en } \\
\text { puerta / portón / } \\
\text { diferentes } \\
\text { tamaños }\end{array}$} \\
\hline & Bocallave & $\begin{array}{l}\text { Recortado } \\
\text { lámina r }\end{array}$ & $\begin{array}{l}\text { on cincel en } \\
\text { lartillada }\end{array}$ & & \\
\hline \multirow{2}{*}{ Candados } & $\begin{array}{l}\text { Candado de } \\
\text { barra }\end{array}$ & Forja cal & ente / fría & \multirow{2}{*}{ No figurativa } & \multirow{2}{*}{$\begin{array}{l}\text { Seguridad en } \\
\text { puerta / portón / } \\
\text { diferentes } \\
\text { tamaños } \\
\end{array}$} \\
\hline & $\begin{array}{l}\text { Candado con } \\
\text { remaches }\end{array}$ & $\begin{array}{c}\text { Forja en cali } \\
\text { Ilave }\end{array}$ & $\begin{array}{l}\text { nte y guarda } \\
\text { ierro) }\end{array}$ & & \\
\hline \multirow{4}{*}{ Llamadores } & $\begin{array}{l}\text { Martillo } \\
\text { simple }\end{array}$ & \multirow{4}{*}{\multicolumn{2}{|c|}{$\begin{array}{c}\text { Forja / fundición / molde de } \\
\text { arena } \\
\text { bronce / hierro }\end{array}$}} & No figurativa & \multirow{4}{*}{$\begin{array}{l}\text { Llamar a la } \\
\text { puerta / portón / } \\
\text { diferentes } \\
\text { tamaños y } \\
\text { formas }\end{array}$} \\
\hline & $\begin{array}{l}\text { Cabeza de } \\
\text { león }\end{array}$ & & & Figurativa & \\
\hline & $\begin{array}{c}\text { Marinos } \\
\text { Iguana } \\
\end{array}$ & & & $\begin{array}{l}\text { Figurativa } \\
\text { Figurativa } \\
\end{array}$ & \\
\hline & Híbridos & & & $\begin{array}{l}\text { No figurativa } \\
\text { /figurativa }\end{array}$ & \\
\hline
\end{tabular}


Fuente: Elaboración propia.

\subsection{TIPOLOGÍA, ICONOGRAFÍA Y DEFINICIÓN DE PUERTAS, PORTONES Y HERRAJES ARTÍSTICOS}

Sobre la puerta, De Amesti (1982) señala que "es el elemento que más piezas de forja posee en los siglos XVII, XVIII y casi hasta la mitad del siglo XIX" (p. 70). Son elementos arquitectónicos ancestrales con valor utilitario, estético y simbólico. De esta manera, representan el paso entre dos mundos, entre "dominios opuestos con valor dinámico psicológico, pues no solamente indica un pasaje sino también el atravesarlo" (Chevalier y Gheerbrant, 2007, p. 855). En este sentido, estos dominios se anteponen: lo sagrado frente a lo profano. Es común encontrar, en los pórticos de las catedrales, la figura del Cristo glorioso que prefigura el texto bíblico: "Yo soy la puerta; el que por mí entrare, será salvo; y entrará, y saldrá, y hallará pastos" (Reina-Valera, 1960, Juan 10:9). Esto se deriva de la tradición simbólica de la puerta dentro del judaísmo. Ahora bien, desde un punto de vista profano y funcional, la puerta es la barrera, el umbral, entre el dominio particular y el mundo exterior. Los herrajes, tales como llamadores, solicitan el ingreso a la intimidad del espacio privado, así como las cerraduras preservan la intimidad.

Una característica relevante de los portones de catedrales e iglesias es la monumentalidad en cuanto a las dimensiones (véase Figura 1). Estas estructuras no solo están diseñadas para los ritos litúrgicos, como las entradas procesionales con imágenes de andas, sino también para evocar humildad ante la grandeza del Reino de Dios. De acuerdo con la investigación de herrajes y puertas en Cuzco de Hostnig (2010), "las longitudes varían entre 3, 8 y 7 metros, la anchura entre 4, 4 y 5 metros; mientras que el espesor alcanza aproximadamente 20 a 23 centímetros" (p. 4). Para una mejor comprensión de las dimensiones reales, se incluye la representación de un monje en la Figura 1, puerta "a". Esta Figura 1 presenta los cuatro tipos principales de portones y puertas, así como la altura promedio de fijación de aldabas y aldabones.
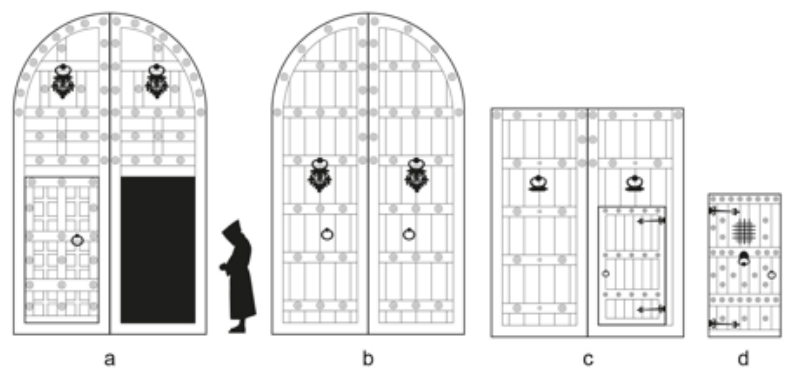

FIGURA 1

Tipología de portones y puertas coloniales

a) Portón de iglesia o catedral de bastidor tipo cuadros: travesaños verticales y horizontales, uno o dos portillos para el ingreso simple de personas, de manera común, con dos hojas y remate de arco ojival o medio punto; b) portón de iglesia o catedral de bastidor tipo marco: tablones horizontales equidistantes y a vista exterior, con remate de arco o cuadrado; c) portón señorial: usualmente de un portillo, recargado de herrajes y con bastidores de cuadros o marco; d) puerta colonial simple: menor tamaño y con bisagras, rejillas y herrajes varios. Fuente: Elaboración propia.

Para facilitar la apertura y evitar el descode de las puertas se utilizaba un elemento heredado de los romanos: el quicio. Según Hostnig (2010), es "un dado de piedra con orificio donde se encaja el espigón de la puerta en la parte inferior" (p. 5). Como se puede constatar por las medidas de las puertas de templos católicos coloniales, estos representaban una inmensa tarea para los talleres que los elaboraban, los cuales contaban con los mejores maestros carpinteros, herreros y cerrajeros.

Por su parte, los bastidores de madera para portones y puertas de doble hoja eran armazones donde los tablones y los herrajes se integraban de manera armoniosa (véase Figura 1). Se pueden encontrar dos tipos fundamentales: en primer lugar, bastidor de marco, para travesaños horizontales y de grosor similar, colocados de manera equidistante. En segundo lugar, los de encuartonado [sic] (o cuadros), en los que "los 
travesaños horizontales son divididos por otros verticales" (Hostnig, 2010, p. 5). Estos portones podían tener de uno a dos portillos, definidos como "puerta pequeña horadada en una más grande" (Mollet, 2002, p. 297).

Asimismo, estos tipos de bastidores para portones se adaptaron para las puertas de casonas y haciendas señoriales de clases dominantes. Al respecto, De Amesti (1982) afirma: "Las casas de cierta importancia contaban con una puerta grande que se abría para que entrase el ganado y los carros y encajada en ella existía otra más pequeña llamada de «cancela», utilizada para la entrada de personas" (p. 70). Entonces, había puertas de doble hoja, con una altura considerable, pero menor que la de los portones de iglesia, pues los dueños de la casa podían ingresar a caballo, carreta o en carruaje. También, es por ello que los llamadores y aldabas se encontraban en una altura superior, no accesible al peatón común. Muchos de estos portones señoriales poseían portillo, tanto para el ingreso como para la salida de la servidumbre. En algunos casos, los sirvientes, criados y esclavos ingresaban y salían por la parte posterior de la vivienda, mediante una "pequeña puerta llamada postigo" (Mollet, 2002, p. 297). Existe una variante evolutiva de la puerta simple "a mediados del siglo XIX, las puertas son de una sola pieza, suprimiéndose las de cancela y siendo habitual que tengan tres falsas bisagras grandes" (De Amesti, 1982, p. 71).

Las puertas más sencillas estaban destinadas a las casas coloniales, de menor dimensión, y, una gran mayoría, tenía una pequeña puerta (similar a las portezuelas laterales y traseras de los carruajes), a la altura del rostro, para identificar y hablar con los visitantes. Esta pequeña puerta estaba resguardada por una rejilla de forja. Las puertas de hacienda señorial e, incluso, de casas más sencillas se caracterizaban por el uso recargado en herrajes como bulas, clavos, llamadores y goznes, a manera de bisagras, pues, al ser muy onerosos, reflejaban el poder económico de la familia, así como su estatus social en la ciudad.

Los herrajes artísticos se pueden definir como productos de la fundición y la forja, consisten en la depuración del óxido de hierro; con hornos de alta temperatura se separa la escoria y la materia prima ferrosa, eliminando materias extrañas y exceso de carbón. Entre más puro, el metal resulta mayormente dúctil para la forja "el hierro utilizado por los herreros a finales del siglo XVIII tenía un bajo contenido de carbón, un 0,04 \%, por lo que se podía considerar casi puro" (Reyneri, 2006, p. 9).

Los herreros efectuaban varias pruebas con el metal de forja antes de realizar los herrajes: en primer lugar, probaban la elasticidad, esta prueba consistía en golpear y doblar el metal para luego enderezarlo repetidas veces y comprobar la no ruptura en el punto de flexión. En segundo lugar, comprobaban la homogeneidad mediante el reiterado plegado de una barra de metal, posteriormente, con un corte se cercioraban que las capas no se separasen entre sí. Finalmente, verificaban la compresión, esta prueba consistía en reducir una barra cilíndrica mediante golpes de mazo a la tercera parte del tamaño original sin rupturas en el material.

Con el tiempo se incorporaron otros metales como el zinc para lograr un material de mayor volumen y para facilitar el trabajo. A eso se le llamó hierro dulce y se desarrollaron variadas técnicas de forja entre las que destacaba la forja catalana, esta técnica supone tratar al hierro con horno abierto de carbón de leña, "la acción combinada del óxido de carbono y del carbón reduce el material a hierro metálico y se sueldan en una gran masa que posteriormente es sometida a la limpieza de escorias" (Reyneri, 2006, p. 29). Asimismo, el sistema de Bérgamo fue muy utilizado en el siglo XVIII y se fundamentaba en la preparación del hierro a partir de la mezcla de hierro colado en un horno capaz de soportar altas temperaturas. Según Reyneri (2006), "se debe quemar carbón de leña en un horno, cuando está en plena combustión se añade poco a poco barras de hierro colado" (p. 30).

Luego de obtener un material depurado y apto para la forja, se utilizaban diversas técnicas. Dentro de las más usadas estaba la calda normal. En esta técnica se calentaba el material a temperaturas entre los $650{ }^{\circ} \mathrm{C}$ y $\operatorname{los} 900^{\circ} \mathrm{C}$ (inferior a eso, el hierro podía agrietarse y superior a esto podría llegar al punto de fundición, lo que imposibilitaría el modelado por golpe. Asimismo, otra técnica empleada era el temple que, luego de enrojecer el metal por calor, se enfría súbitamente con agua, aire o aceite (Reyneri, 2006, p. 30). Para unir los forjados en piezas complejas se utilizaba la soldadura autógena, la cual "se obtiene llevando el hierro a la incandescencia 
blanca a temperatura de $1300{ }^{\circ} \mathrm{C}$ y $1500{ }^{\circ} \mathrm{C}$, a esa temperatura el metal tiene la propiedad de soldarse sin interposiciones de otro metal y ser correctamente sometido al golpe de mazo" (Reyneri, 2006, p. 31).

No todos los herrajes eran elaborados mediante forja, algunos son producto de la fundición. Se pueden señalar dos métodos de fundición de herrajes, sobre todo, para la elaboración de llamadores, bulas y mascarones. El primero, la fundición de cera perdida (Langland, 1999, p. 17), consiste en modelar en barro un original y obtener una forma negativa. Esto se lograba mediante un molde de yeso, posteriormente, se vierte cera de abeja mezclada con otros componentes. Estos, a su vez, después de colocar tubos de cera (también coladas) para la salida de gases y vertido del metal, se preparan en un molde final que soporte el calor extremo (usualmente de yeso y ladrillo refractario molido). Al ser calentado, el segundo molde la cera sale en forma de gas y deja una forma negativa que contendrá el metal fundido. Por último, se rompe el molde, se eliminan las coladas y se dan los acabados a la pieza.

El segundo método es el molde de arena, este sistema básicamente es para duplicar piezas existentes. Primero se prepara un cajón de madera dividido en dos partes. Luego, la arena es cernida y mezclada con melaza para aglutinarla, se llena la primera mitad y se imprime la pieza con fuerza de maza de madera. En la segunda mitad se termina la copia de la pieza y, después de retirar el positivo, se perforan canales de acceso para el metal fundido y salida de gases. Este método aún se utiliza para herrajes en La Antigua, Guatemala.

\subsection{Tipología de lOS HERRAJEs, ALDABA Y ALDABÓN}

Según el Diccionario de la Real Academia Española (DRAE, 2020), la palabra aldaba ${ }^{5}$ tiene las siguientes acepciones:

1. Del árabe clásico "aḍ-dabbah" (مطرقة) que significa literalmente "lagarta" o forma semejante a reptil, pieza de hierro o bronce que se pone en las puertas para llamar golpeando de ella, 2. Pieza, ordinariamente de hierro y de varias hechuras, fija en la pared para atar la caballería, 3. Barreta de metal o travesaño de madera con que se aseguran los postigos de madera o puertas (párrs. 1-3).

Según De Amesti (1982), "en el siglo XVII, XVIII y principios del XIX, la aldaba de forja tuvo gran auge hasta que fue sustituida por aldabas de fundición, de hierro o de latón” (p. 71). El aldabón se distingue de las aldabas normales básicamente por su tamaño. En este sentido, la forma más típica, y, seguramente, también la más antigua, es una simple argolla de metal, unida a una cabeza, hecha generalmente de bronce moldeado. "Estas argollas, aparte de servir como llamadores, en las puertas grandes y pesadas facilitaban también su apertura y cierre, puesto que también funcionaban de tiradores” (Hostnig, 2010, p. 6). El lugar más común son los portones de catedrales, muchas veces con emblemas relacionados con la iglesia.

Los motivos de animales, como el del perro, el león y el mono, son comunes. Chevalier y Gheerbrant (2007) dicen lo siguiente con relación al valor simbólico del perro: "La función mítica del perro, es la de guía del hombre en la noche de la muerte, tras haber sido compañero en el día de la vida” (p. 816). En este sentido, en la Figura 2 las imágenes "a" y "e" muestran representaciones caninas como símbolos de la fidelidad. En "a" el perro se representa dentro de un conjunto simbólico con querubines, la virgen y las uvas, como fruto de vid cristiana y materia de comunión. Asimismo, otros motivos de animales suponen una carga simbólica antes que un aporte meramente estético. Se recomienda contrastar la Figura 2 con la Figura 9 para percibir algunas variables dentro de un mismo tipo de herraje. 


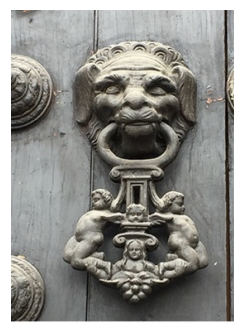

a

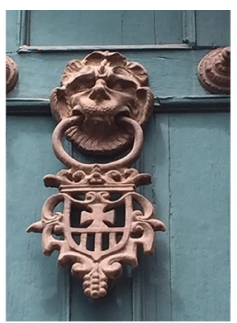

b

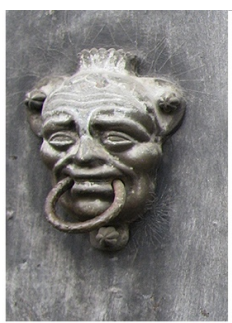

C

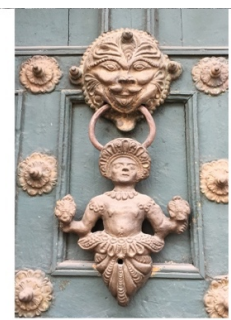

d

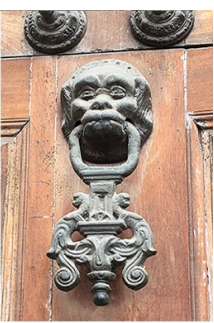

e

FIGURA 2

Tipología de aldabones de cabeza zoomorfa y antropomorfa de tipo grotesca a) Perro con querubines renacentista, uno de cabeza alada en el centro. En la parte inferior, la Virgen de las uvas, referencia eucarística, además de las bodas de Caná; b) mono con escudo inspirado en la orden Merced de Castilla, con detalle de uvas eucarísticas y florituras de acanto; c) antropomorfa grotesca con aldaba simple y bulas de fijación floral tipo bulbo; d) antropomorfa grotesca con apéndice colgante en aldaba, arquetipo de india americana

6 con hojas de tabaco en cada mano y atavíos prehispánicos; e) perro con dragones florales simétricos y voluta. Fuente: Elaboración propia.

\subsection{Tipología de los herrajes, ARgollas y ARgollón}

Los herrajes de este tipo son anillos unidos a una espiga de cuña. Están fijados a los muros o las puertas, existen de varios tipos: en primer lugar, el argollón de cuña (véase imagen "a" en la Figura 3), para un muro de mayor tamaño y peso que las argollas comunes. Los argollones se utilizaban con diversos fines: atar caballos, amarrar las embarcaciones a los puertos, inmovilizar presos y vender esclavos. La argolla de cuña se incrustaba a fuerza de mazo en la roca de cantería, usualmente en las fachadas o tras patios. El segundo tipo de herraje es la argolla retorcida de puerta (véase imagen "b" en la Figura 3), la cual se usó principalmente como tirador de puerta. La forma de rizo se logra forjando el metal al rojo vivo mediante una barra doble. Se produce una torsión uniforme en la barra metálica previamente martillada con el objetivo de perfilar las cuatro caras. El tercer tipo de herraje es la argolla simple redonda, trabajada mediante yunque en su extremo cónico para lograr la circunferencia elegida (véase imagen "c" en la Figura 3), son las más comunes y sirven también como jalador de puerta. Finalmente, el cuarto tipo de herraje es la argolla para caballo (puede ser articulada o no), es una argolla con una espiga vertical, para asegurar las riendas del animal. En algunos casos, se decoran con motivos equinos y son usadas regularmente en los zaguanes ${ }^{7}$.
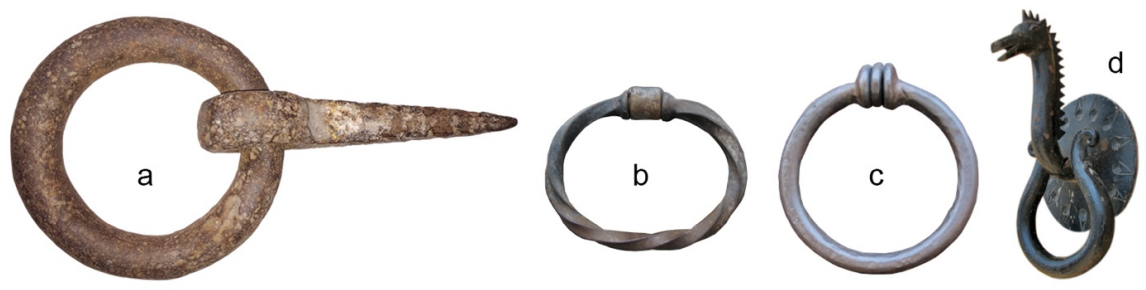

FIGURA 3

Tipología de argollas de forja

a) Argollón de cuña para muro en forja catalana (s. XVI-XVII aprox.); b) argolla de puerta retorcida en forja (s. XIX); c) argolla simple redonda forja martillada (s. XIX aprox.); d) argolla para caballo de forja y limado en frío (s. XVIII aprox.).

Fuente: Elaboración propia.

\subsection{Tipología de los herRajes, BULA}

Según Mollet (2002), bula "designa objetos de varios tipos con forma de burbuja de agua. Algunos picaportes reciben el nombre de bulae” (p. 76). Entre los principales tipos en puertas coloniales y republicanas 
tempranas, se halla festonado, labrado, floral, redondeado, tetilla o chupón, labrado-calado (véase Figura 4). Las bulas más antiguas fueron fundidas en bronce antiguo "compuesto solamente con estaño y cobre" (Mollet, 2002, p. 66), aunque se encuentran también en hierro y cobre. La gran mayoría tiene el clavo de herrero inserto en la parte central. En las versiones de la segunda mitad del siglo XIX, se incorpora el tornillo como elemento de fijación a la madera o el cintillo de metal.

En la Figura 4, en la imagen "e" se puede apreciar una bula con calado de influencia turca. Estos discos calados para clavos se usaban en las puertas de hierro ubicadas en los edificios eclesiásticos dedicados a la enseñanza del Corán, sobre todo, en Estambul. Fueron construidos por los sultanes y califas en mezquitas y bibliotecas. Los más antiguos datan de la segunda mitad del siglo XV hasta la primera mitad del siglo XVI, aunque se popularizan en el siglo XVIII (Burton, 1934, p. 224).

Las bulas eran de suma relevancia dentro de la Colonia, con ellas se demostraba al resto de la comunidad el poder económico de la familia. Un parámetro del valor de los productos de la forja en tiempos coloniales se encuentra en las actas del cabildo de Guatemala de 1524, donde se fija el precio para los herreros de los clavos de forja "dos pesos por cien clavos y poniendo los herreros el hierro tres pesos" (Domínguez, 1987, p. 103). Por lo anterior, los portones señoriales se encuentran profusamente decorados con este tipo de herrajes. En dichos portones, se imita la estética religiosa católica, incluso, en algunos casos, estas composiciones reflejan un terror al vacio de parte de sus clientes o compositores. Además, presentan cualidades estéticas del diseño barroco en los siglos XVII y XVIII.

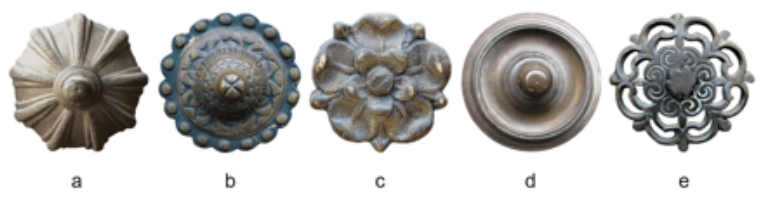

FIGURA 4

Tipología de bulas para fijación de tablones y decoración exterior

a) Festonado fundido; b)fundido y labrado en frío; c) floral fundido;

d) redondeado o chupón fundido; e) fundido y labrado-calado en frío. Fuente: Elaboración propia.

Ahora bien, como se puede apreciar en la Figura 4, las variaciones de estilo de las bulas fueron muy diversas. Las más costosas eran aquellas que, tras su fundición, se labraban para lograr espacios negativos en la pieza (véase "e" en Figura 4). A pesar de ello, las más populares fueron las de tipo festonado fundido (véase "a" en Figura 4) que alcanzaban, en promedio, hasta 18 centímetros de diámetro máximo. La mayoría de los ejemplares de bulas festonadas, usualmente de bronce, permanecen hasta la actualidad en las puertas y los portones de las catedrales andinas.

\subsection{Tipología de los herRajes, llaVes de FORJA, BocallaVes y LLAVES FUndidas LABRADAS}

La principal cualidad para distinguir las llaves de forja es su tamaño. En este sentido, las llaves de portón, generalmente, poseen dimensiones superiores a los $15 \mathrm{~cm}$ y guardan un orificio para encajar en el eje del mecanismo de la cerradura; por medio de este la llave gira hasta empatar el gancho exterior de la llave con el dentado que desliza la barra interna de la cerradura hacia la izquierda para cerrarla o a la derecha para abrirla. Dicho esto, existe una gran variedad de formas y tamaños en llaves; de las muestras más antiguas conservadas se encuentran las romanas, elaboradas en hierro y bronce. Las llaves de la Edad Media suelen ser simples y sin decoración, diseñadas exclusivamente para la utilidad, mientras que "las llaves góticas a menudo están elaboradamente concebidas y decoradas" (Hoffeld, 1969, p. 169). 
En el siglo XVI, en Florencia y Milán, los artesanos cerrajeros decoraban las llaves con finos y complejos motivos tales como florales, estilizados geométricos de influencia morisca, figurativos de orden mitológico greco-romano, símbolos cristianos como cruces, peces y ángeles en los mangos de llave. Véase, por ejemplo, la imagen "b" en la Figura 5, una base fundida genérica en la que el cerrajero recortó la combinación particular de la cerradura; las llaves de candado de forja, usualmente, eran más rústicas, sin labrados especiales y de mecanismo simple, y con mucho menor tamaño (entre 4 y $8 \mathrm{~cm}$ aprox.).

Para preservar la integridad de la puerta y, a su vez, proteger el mecanismo de la cerradura del agua o suciedad y dirigir la llave de manera exitosa, se elaboraban bocallaves, formas caladas en láminas de hierro con siluetas de escudo heráldico de familia, motivos religiosos y repujados decorativos de tipo simétrico. Sobre la bocallave, De Amesti (1982) señala que "pueden ser de muy variadas formas y tamaños, pero siempre plana y de dibujo simétrico. A partir de mediados del siglo XIX las bocallaves son de formas más simples” (p. 71).

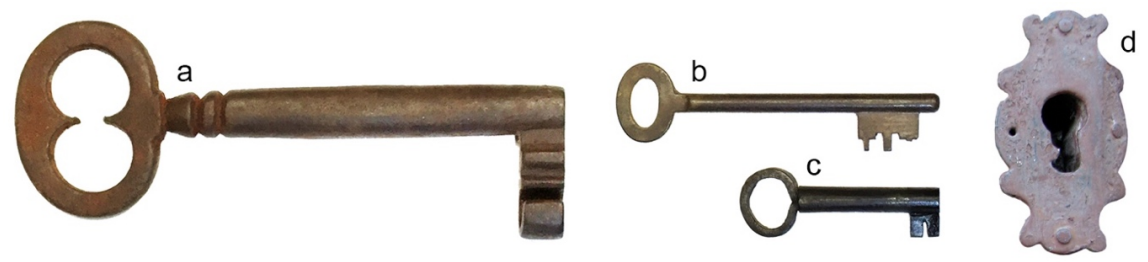

FIGURA 5

Tipología de llaves y bocallaves

a) Llave de portón fundida y labrada; b) llave de puerta fundida y labrada; c) llave de candado fundida y labrada; d) bocallave recortada con cincel de lámina martillada. Fuente: Elaboración propia.

\subsection{Tipología de LOS HERRAJES, CANDADOS DE FORJA}

Inicialmente, los candados eran usados en cofres o baúles. El uso de cerraduras externas, tipo candado, se popularizó con la disminución de los herreros especializados en forja y, además, con la pérdida de las llaves de las cerraduras de tipo portón. Así, la mayoría de los candados se aseguraban entre aros metálicos de tipo clavo (se dobla el extremo excedente por el lado interno de la puerta). Las incrustaciones de los clavos se hacían en el marco del bastidor estructural de la puerta, en el marco del portal, en caso de que fuera una puerta; entre bastidores, en el caso de puertas dobles (véase Figura 6, imagen "c"). En todo caso, la función del candado de forja en la Colonia era la misma que posee actualmente: resguardar del robo, impedir el paso y reservar el acceso al contenido a quien tenga en su poder la llave. Finalmente, en la segunda mitad del siglo XIX, se fabricaron candados ferroviarios y de tipo corazón, con tecnología mucho más elaborada, en cuanto al engranaje liberador, en comparación con las técnicas del siglo XVIII.

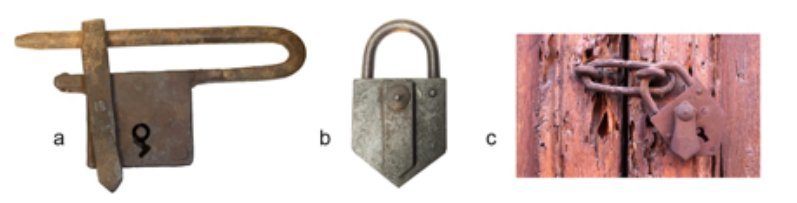

FIGURA 6

Tipología de candados de forja en hierro (herrajes de seguridad)

a) Candado de barra forjado (hierro); b) candado con remaches de forja en caliente y guarda llave, en material de hierro; c) ejemplo de montaje candado de forja entre clavos de argolla incrustados en la madera.

Fuente: Elaboración propia. 


\subsection{Tipología de los herrajes, MAScarones de PORTAL}

Los herrajes tipo mascarones de portal fueron populares, desde el renacimiento hasta el siglo XIX, sobre todo, en edificios oficiales. En estos edificios se incorporaban a las fachadas mascarones y escudos con rostros femeninos (náyades), faunos, leones y otros (véase Figura 7). Poseen la particularidad de que son figuras modeladas o talladas, con mayor volumetría, colocadas en la parte superior de las fachadas o pórticos de edificios. Asimismo, se encuentran casos de mascarones con talla directa en puertas de madera.

Los mascarones de pórtico o portal, inicialmente, eran productos de cantería que se incorporaban dentro del proceso constructivo. La talla en piedra implicaba conocimientos de material pétreo, así como especialización específica. Se encuentran muchos ejemplares en las catedrales medievales, así como en los mausoleos en donde los canteros de gremios organizados transmitían sus conocimientos a quienes estaban dentro del círculo familiar y, en ocasiones, cultural. Los artesanos europeos medievales, a causa de compartir la misma procedencia y el mismo idioma, crearon elaborados productos culturales, como la talla en piedra y forja, las cuales experimentaron una derivación de estilo con el perfeccionamiento del proceso de fundición durante el Renacimiento y la posterior refinación estilística del Barroco. Mientras que para los artesanos herreros y orfebres de la América colonial el uso del bronce fundido, así como del cobre martillado, supuso la posibilidad de diversificar la producción de objetos de uso común a objetos decorativos ahora destinados a embellecer y a distinguir a los individuos dentro del continuum social.

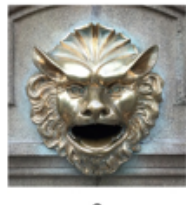

a

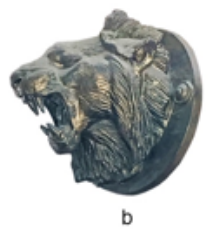

FIGURA 7

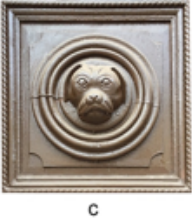

Tipología de mascarones de fachada, portal, pórtico y puerta

a) León fundido en cera perdida para fachada, en material de bronce pulido; b) león fundido en cera perdida para portal, en material de bronce patinado; c) can tallado en panel de puerta, en material de madera.

Fuente: Elaboración propia.

\subsection{Tipología de los HeRrAJES, LlAMADOR DE MARTILlo SIMPLE O FALIFORME}

Este tipo de llamador se encuentra en zonas rurales de España, sobretodo, en Aragón. Según Colomina et al. (1983), "es traído como estilo al nuevo mundo por herreros migrantes de estas zonas, muy posiblemente está relacionado a cultos o ritos mágico-religiosos de fertilidad profanos vinculados a la vida agrícola” (p. 61). Posteriormente, son asimilados por el catolicismo en festividades de santos, como la de la virgen de los Dolores para el buen parto o San Ramón Nonato para las embarazadas. La necesidad de un fetiche de fecundidad en el mundo rural está relacionada con el ganado, la tierra, el acceso al agua e, incluso, como amuleto de casa para la fertilidad humana, pues, para las creencias judeocristianas, la infertilidad es un castigo, "la expansión del cristianismo supuso la sustitución simbólica o cristianización de los símbolos paganos" (Colomina et al., 1983, p. 61).

Los llamadores de martillo surgen en Europa, entre los siglos XI-XIII, son de manufactura simple, pues consisten en un martillo que, articulado a un espigón doble incrustado en la madera, es fijado por una placa, la cual impide la salida de la pieza y sirve también para la fijación. La pieza metálica, elemento receptor del golpe, recibe el nombre de tas y repercute en la madera de forma acústica. Esto incrementa el sonido del llamador y salvaguarda la integridad de la madera (véase Figura 8). 

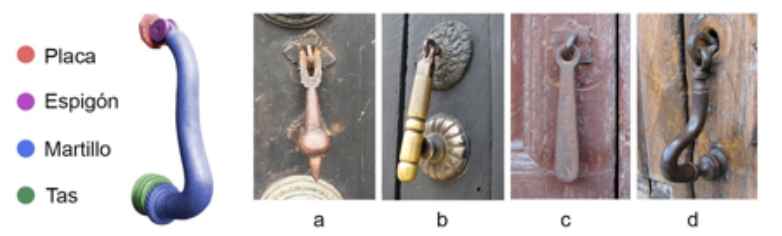

FIGURA 8

Tipología de llamadores de martillo simple o faliforme

a) Hierro forjado en caliente y labrado en frío; b) fundición de cera perdida, en material de bronce; c)
fundición en hierro por molde de arena; d) fundición de cera perdida, en material de hierro colado.
Para mejor comprensión, se ha aplicado color a cada una de las partes del llamador de martillo. Fuente: Elaboración propia.

\subsection{Tipología de los herRajes, LlaMAdor CABEZA DE LEÓN}

Los llamadores cabeza de león obtuvieron su estética por causa de los mascarones europeos de los siglos XVII y XVIII, los cuales están ubicados en las piedras clave de los arcos y bajo los balcones de piedra. Los balcones de piedra poseen un carácter serio o grotesco, con tendencia de rostros de animales de tipo cabossed o "animal decorativo que solo muestra el rostro" (Mollet, 2002, p. 69). De igual manera, son figuras modeladas y representan el tema más recurrente en llamadores de puerta: representaciones felinas, las cuales van desde las estilizaciones antropomorfas hasta las literales, desde el punto de vista anatómico (véase Figura 9).

En Cartagena de Indias, el llamador de león se relacionaba con las familias de ascendencia noble y con los mandos militares, clara reminiscencia a los escudos heráldicos reales y nobles de Europa. Es muy posible que la asimilación de este motivo estilístico se difundiera entre familias que no poseían ese abolengo, hasta convertirse en el segundo motivo más popular. Por su parte, en el caso de La Antigua, Guatemala, el motivo leonino es el más común, se encuentra en muchas puertas más modestas que los portones señoriales. De hecho, gran cantidad de piezas carecen de partes por robo o pérdida de la aldaba llamadora. Quizá esto se deba a que este llamador, al igual que las herraduras equinas, es un símbolo de suerte y buen augurio.
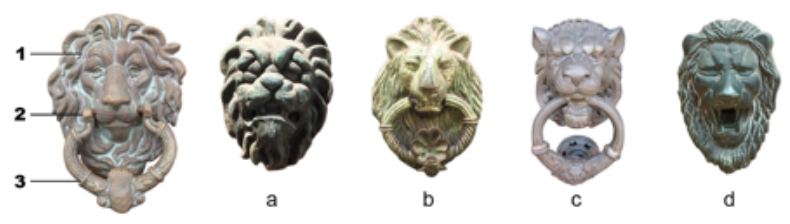

FIGURA 9

Tipología de llamadores cabeza de león

La mayoría son fundidos mediante dos sistemas: el primero, por molde de arena y, el segundo, por cera perdida. Los primeros son los más comunes en América Latina. Las partes fundamentales son cabeza (1) pivote (2) y argolla

(3); los ejemplos (a, b, c, d) son una muestra de las diversas variantes dentro de las representaciones del león.

Fuente: Elaboración propia.

\subsection{Tipología de los herRAJES, LLAMADORES MARINOS}

El caso de Cartagena de Indias es particular. En sus puertas, se pueden apreciar llamadores de puerta con estilos relacionados con el tema marino: sirenas, peces y otros (véase Figura 10), lo cual no se encuentra en el resto de colonias españolas. Esto revela la importancia y el nivel de reconocimiento de la sociedad de Cartagena como puerto colonial, de entrada o salida comercial del Virreinato. A diferencia de otras colonias españolas, muchos de los motivos o estilos que fueron elaborados aún se fabrican íntegramente en esta ciudad. 


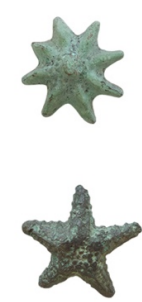

a

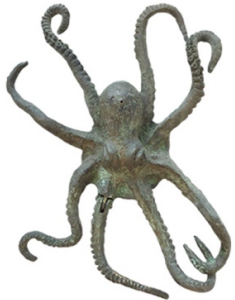

b

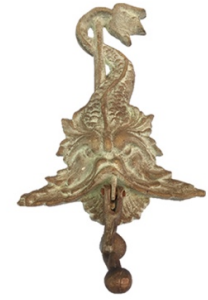

C

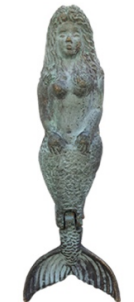

d

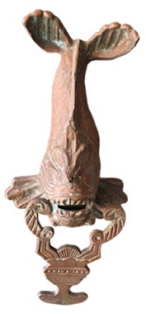

e

FIGURA 10

Tipología de bulas y toca puertas marinos

La mayoría son fundidos con molde de arena. Las formas más planas son bidimencionales (arena) y por cera perdida las más volumétricas (fundición). a) bulas con forma de concha marina y estrella de mar; b) pulpo de brazo espiga móvil; c) pez estilizado tipo renacentista, usado también en botaguas y fuentes; d) sirena de cola espiga móvil, inspirada en grabados de leyendas marinas; e) ballena estilizada con cáliz, inspirada en grabados de monstruos marinos. Fuente: Elaboración propia.

La tradición oral popular sostiene el hecho de que los herrajes de Cartagena representan la mayor colección y patrimonio de toca puertas o llamadores de América Latina. Además, que muchos de los motivos fueron adoptados por las familias como medio de diferenciación y estatus, el cual, en algunos casos, no era de herencia familiar: "En el siglo XVII la corte se mostró más abierta a la concesión o venta de títulos" (Durand et al., 1992, p. 57). Mientras tanto, en otros casos, la nobleza se adquiría mediante matrimonio: "Algunos indios nobles se casaron con españolas, - como don Martín Montezuma o Moctezuma (según traductor), hijo del emperador, y don Constantino Huitzimengari, sucesor del cazonci o rey de Michoacán" (Carrasco, 1991, p. 8). Los criollos venidos a menos todavía mantenían sus pretensiones nobiliarias: "A fines del siglo XVI y principios del XVII, y aún después, los criollos mantienen el mismo porte soberbio y el mismo afán de notoriedad; pero ya el dinero les falta y del antiguo esplendor sólo vive el recuerdo" (Durand et al., 1992, p. 48).

Los llamadores marinos estaban relacionados con mercaderes acaudalados que comerciaban con productos del mar, los de leones estaban ligados a los mandos militares y, por último, las iguanas marinas estaban conectadas con los descendientes de familias con algún ligamen noble cartagenero (véase Figura 11).

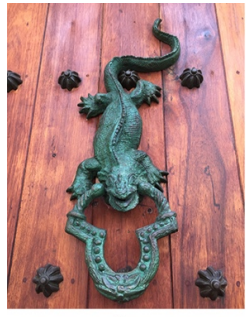

a

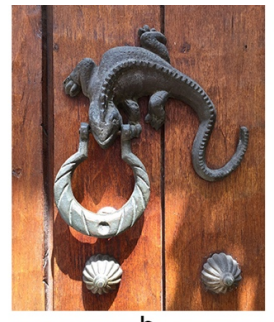

b

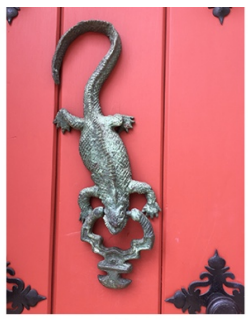

C

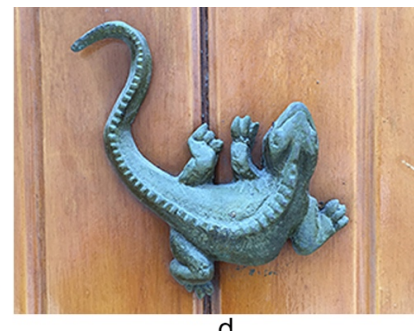

d

FIGURA 11

Tipología de herrajes, llamadores iguana marina (Cartagena de Indias)

De forma casi volumétrica, son el resultado de la observación de la fauna autóctona costera latinoamericana y se adoptan como símbolo de nobleza y pertenencia en Cartagena de Indias a partir del s. XVIII. a) fundición en arena, con argolla decorada por volutas, motivos florales y geométricos; b) fundición en arena, con argolla tipo herradura labrada; c) fundición en arena, con argolla decorada por volutas, motivos florales y geométricos; d) figura de iguana decorativa con espiga de anclaje en puerta (fundición moderna, s. XX). Fuente: Elaboración propia.

\subsection{Tipología de los herRAJES, otros Motivos CoMUNES DE LLAMADORES}

En primer lugar, debe considerarse que los conquistadores se ubicaron en la cima del sistema de castas colonial. Así, con el surgimiento de nuevos poderes en los criollos y mestizos, "llegó a la Colonia una nueva 
aristocracia, en la cual el título de conquistador se reconocía valioso y hasta comparable a los títulos de Castilla" (Durand et al., 1992, p. 45). Los estilos variaron según los gustos de los encargos, así como por la propia improvisación creativa de quienes los producían. Por esto, a finales del siglo XVIII y a principios del siglo XIX, se encuentra un abanico de posibilidades en los toca puertas, entre los que destacan los motivos de animales y flores (véase Figura 12). Todos ellos bajo el común denominador de la figuración. Sería mucho tiempo después que surgirían, con las vanguardias del siglo $\mathrm{XX}$, los llamadores no figurativos y más geométricos.

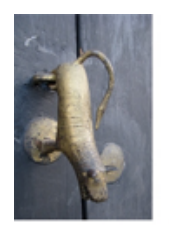

a

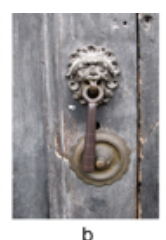

b

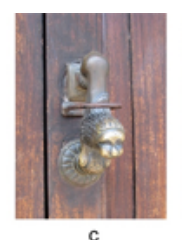

c

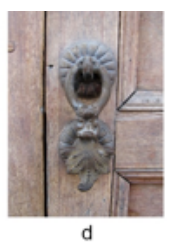

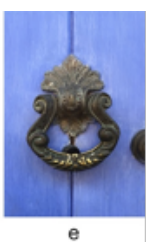

e

FIGURA 12

Motivos híbridos figurativos de llamadores de puerta

a) Llamador con la representación de la figura canina; b) llamador de cabeza grotesca, con espigón faliforme y tas bula de chupón; c) llamador con la representación de la figura leonina (cancelado o no funcional), con tas de bula floral; d) llamador de argolla con hoja de parra, con volutas y tas bula floral; e) llamador de argolla tipo herradura, con hojas de acanto y tas simple. Fuente: Elaboración propia.

\subsection{Tipología de los herrajes, coincidencias tipológicas de los herrajes en laS CIUDADES QUE CONFORMAN LA MUESTRA}

Una de las inquietudes que originó este estudio fue la posibilidad de encontrar patrones comunes con relación al tema del uso de herrajes en las cuatro ciudades. En este sentido, según la muestra, efectivamente, se encuentran coincidencias de uso y técnica, pero no de uso y estilo (con excepción del caso Cuzco-Arequipa), ya que los herrajes, a nivel estético o ejecución artística, son tan disímiles como quienes los produjeron. Sin embargo, se pueden extraer varias conclusiones circunstanciales, a partir de la coincidencia, así como otras a partir de la exclusividad.

En la Tabla 2, se muestran los herrajes presentes por zona (cuatro ciudades). En esta tabla se identifica un $100 \%$ de presencia en la muestra de puertas coloniales simples. Esto quizá sea posible porque eran las más comunes por su valor asequible con respecto a los portones de grandes dimensiones, los cuales, posiblemente, sobrevivieron al uso a través del tiempo, ya que sus bisagras soportaron mucho menos peso. Asimismo, se encuentran aldabas y aldabones de cabeza zoomorfa, motivo recurrente y con peso simbólico en el caso de las representaciones de leones y otros animales relacionados con las virtudes de lealtad, valor y nobleza.

De igual manera, otros herrajes de menor tamaño se pueden rastrear en las cuatro ciudades: argollas de forja (cuña y retorcida), bulas de clavo (festonado, labrado, floral y chupón); usados para mantener la estructura unida de las puertas, así como para la decoración. Este tipo de herrajes pequeños existen, siempre y cuando sobreviva también la puerta. También resisten el vandalismo porque son de difícil extracción. Aunado a esto, en su mayoría, son elementos compuestos de bula perforada, fijada con clavo central. Finalmente, se encuentran llamadores de diversos tamaños, inclusive, en puertas de factura más reciente, tales como martillo simple y cabeza de león, en donde son los de fundición los más comunes y no los de forja.

En lo concerniente al porcentaje de herrajes presentes por ciudad se encontró que un $75 \%$ de la muestra analizada (véase Tabla 2) se encuentra en los portones de iglesias o catedrales y casas señoriales, donde las argollas de forja simple redonda abundan; puesto que son argollas producto de la herrería de taller, es posible entender que se produjeron a golpe de hierro al rojo vivo y no por torsión en frío. Además, el material ferroso está presente más que el bronce en este tipo de argollas más funcionales (abrir y cerrar) que decorativas. Como elemento de seguridad se encuentran candados de barra fijados por argollas simples. Con relación al tema 
de los candados como en el de los llamadores, hay que cerciorarse de que no posean tornillos. El observar la presencia de tornillos en un candado lo situaría temporalmente en el siglo XIX, por lo menos, puesto que la tuerca universal se crea hasta 1841. Este es un método simple de datación o reconocimiento temporal del objeto que, aunque no es exacto, puede situarlo en un espacio temporal determinado y ayuda a diferenciar piezas modernas con aspecto antiguo, como lo son las pátinas químicas que simulan las pátinas de uso u oxidación que aporta el tiempo.

En menor medida con un $50 \%$ de la muestra analizada (véase Tabla 2), se encuentra la aldaba/aldabón de cabeza antropomorfa. Además, en los casos encontrados, se puede ver que las cabezas no corresponden, a nivel de estilo, a una copia mimética de una cabeza humana. En este sentido, son estilizaciones con rasgos faciales exagerados. Asimismo, la bula de clavo labrado calado es poco común. Se deduce que lo laborioso del calado, así como de las herramientas de corte de metal en forja caliente y el subsecuente limado en frío son varios de los aspectos que llevan a la suposición de que el costo final no era competitivo frente a otros herrajes similares. También, son menos comunes los candados con remaches, se debe ser cuidadoso para no confundir los remaches mecánicos modernos (cerrados con presión hidráulica) de la última mitad del siglo XIX y la primera mitad del XX, con los de remache antiguo que consisten en un perno al rojo vivo que se remacha o cierra en el orificio mediante golpes de mazo, en los candados antiguos es característico el remanente o rebaba del final de perno martillado. Finalmente, en un $25 \%$ de la muestra analizada (véase Tabla 2), de manera exclusiva, se encuentran en Cartagena los llamadores y las bulas con motivos marinos. Como símbolo cartagenero, se encuentra la iguana en diversas poses y acabados. En La Antigua, Guatemala, los herrajes híbridos se pueden explicar por la mezcla de motivos y la ininterrumpida producción de herrajes para puerta.

TABLA 2

Tipología de herraje encontrada por ciudad

\begin{tabular}{|c|c|c|c|c|c|}
\hline Tipo & Variables & Cuzco & Arequipa & La Antigua & Cartagena \\
\hline \multirow{2}{*}{ Portones } & Iglesia o catedral & $\bullet$ & $\bullet$ & $\bullet$ & \\
\hline & Señorial & - & - & - & \\
\hline Puertas & Colonial simple & - & - & - & - \\
\hline \multirow{2}{*}{$\begin{array}{l}\text { Aldaba / } \\
\text { Aldabón }\end{array}$} & Cabeza zoomorfa & $\bullet$ & - & - & - \\
\hline & Cabeza antropomorfa & $\bullet$ & $\bullet$ & & \\
\hline \multirow{4}{*}{$\begin{array}{l}\text { Argollas de } \\
\text { forja }\end{array}$} & Cuña & $\bullet$ & $\bullet$ & $\bullet$ & $\bullet$ \\
\hline & Retorcida & $\bullet$ & $\bullet$ & $\bullet$ & $\bullet$ \\
\hline & Simple redonda & $\bullet$ & & $\cdot$ & $\bullet$ \\
\hline & Para caballo & & & $\bullet$ & \\
\hline \multirow{6}{*}{ Bula de clavo } & Festonado & $\bullet$ & $\bullet$ & $\bullet$ & $\bullet$ \\
\hline & Labrado & $\bullet$ & $\bullet$ & $\bullet$ & $\bullet$ \\
\hline & Floral & $\bullet$ & $\bullet$ & $\bullet$ & $\bullet$ \\
\hline & Chupón & $\bullet$ & $\bullet$ & $\bullet$ & $\bullet$ \\
\hline & Labrado calado & & & $\bullet$ & $\bullet$ \\
\hline & Marino & 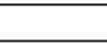 & & & $\bullet$ \\
\hline \multirow{4}{*}{ Llaves } & Portón & $\bullet$ & $\bullet$ & $\bullet$ & $\bullet$ \\
\hline & Puerta & $\bullet$ & & $\bullet$ & $\bullet$ \\
\hline & Candado & - & & - & \\
\hline & Bocallave & $\bullet$ & & $\bullet$ & $\bullet$ \\
\hline \multirow[b]{2}{*}{ Candados } & Candado de barra & $\bullet$ & $\bullet$ & $\bullet$ & \\
\hline & $\begin{array}{l}\text { Candado con } \\
\text { remaches }\end{array}$ & - & & - & \\
\hline \multirow{5}{*}{ Llamadores } & Martillo simple & $\bullet$ & $\bullet$ & $\bullet$ & $\bullet$ \\
\hline & Cabeza de león & $\bullet$ & $\bullet$ & $\bullet$ & $\bullet$ \\
\hline & Marinos & & & & $\bullet$ \\
\hline & Iguana & & & & $\bullet$ \\
\hline & Híbridos & & & $\bullet$ & \\
\hline
\end{tabular}

Nota. Tabla basada en el estudio de campo efectuado en una extensión aproximada de diez cuadras en la periferia de plaza e iglesia mayor, la ausencia de muestra no implica ausencia absoluta. 
Fuente: Elaboración propia.

\section{Conclusiones}

En primer lugar, la existencia de los herrajes para puertas coincide con las ciudades que desarrollaron la industria de forja y la fundición de metal. Esto propició el surgimiento de talleres especializados, la regulación del trabajo mediante ordenanzas y cartas de examen para determinar la pericia y los conocimientos necesarios para ejercer el oficio y pertenecer al gremio, como lo prueba Nieto (2018). Como evidencia de lo anterior, están todas las ordenanzas concernientes al trabajo de herrería, así como las fuentes secundarias. Adicionalmente, la existencia de talleres condicionó la producción de herrajes artísticos en espacios específicos como tiendas, mercados y talleres. Lo anterior explicaría la razón por la cual otras ciudades sin yacimientos de metal e industria organizada (aunque sea primitiva) carecen de este tipo de artefactos.

De igual manera, las órdenes religiosas como franciscanos y dominicos fueron fundamentales dentro de la enseñanza del trabajo del metal a las poblaciones indígenas que no tenían posibilidad de incorporarse a los gremios de herreros en calidad de maestros. Esto también incentivó la migración desde España de maestros artesanos para satisfacer la demanda de herrajes y objetos, en general, de metal forjado y fundido.

Además de eso, en el caso de Cuzco y Arequipa, resulta difícil establecer o diferenciar los herrajes importados de Europa de los producidos en América, como lo explica García (1966) con la importación de utensilios y la emigración de artesanos españoles en el siglo XVII. No obstante, se sabe que la mayoría de los objetos traídos desde España eran para uso doméstico, lo que deja gran parte de la producción de los herrajes de puerta en los talleres locales. La muestra analizada en la Tabla 2 evidencia que existen parámetros comunes en las cuatro ciudades con relación al tema de los herrajes, sobre todo, en las bulas de tipo chupón, los llamadores de tipo cabeza de león y otros, con una coincidencia del $100 \%$ de presencia. Al mismo tiempo, herrajes que solamente están presentes en la ciudad de Cartagena de Indias revelan el elemento diferenciador de estética del motivo marino, sin que ello sea correlativo a una diferenciación del uso o técnica.

La Antigua, Guatemala, revela la fusión de estilos, así como la constante reproducción temática de arquetipos como las cabezas zoomorfas y argollas de forja. Por último, existe una cercanía de estilo, técnica y uso para las ciudades de Cuzco y Arequipa que, pese a la considerable distancia geográfica, hace suponer relaciones comerciales de este tipo de objetos entre las ciudades.

Con respecto a la relación entre estatus social y herrajes de puerta, se demuestra, con los registros de Carreras y Nadal (2002) de las transacciones coloniales, así como en los registros recuperados por Hostnig (2010), el alto valor económico de los herrajes en el mundo colonial. Lo anterior se contrapone a los bajos salarios de los trabajadores, evidenciados por Salas (2004) en su estudio de relación entre el trabajo y la remuneración, lo que prueba el carácter prohibitivo de clases subalternas para el acceso a este tipo de objetos y, en definitiva, para el acceso a la casa señorial o la hacienda colonial. Por tanto, se prueba la relación entre el valor del herraje, su rareza inicial en el mundo colonial y las clases dominantes. Así, existen "objetos que reconocen una clase social, sobre todo en lo que afecta a su valor de intercambio, cuanto más caro más difícil de obtener, y por lo tanto indica un alto estatus social” (Carreras y Nadal, 2002, p. 69).

En una temprana etapa los herrajes utilizaron tipologías específicas que denotaban la actividad o el estatus social de las familias, como se pudo demostrar en el caso de Cartagena de Indias, en donde se desarrollaron llamadores diferenciadores y únicos para esa región. No obstante, en el periodo republicano temprano, estos patrones son adoptados por su valor estético y no como elementos diferenciadores de clases sociales, dicha apropiación se da por los emergentes grupos relacionados con el comercio de bienes varios y por terratenientes.

Finalmente, la construcción de una tipología y nomenclatura de tipos y variables se estableció en la Tabla 1. Es así como el aporte de este estudio consiste en ordenar y ampliar el enfoque tipológico en aspectos técnico- 
estéticos. No se pretende, de ningún modo, establecer la tipología presentada como definitiva, sino como un punto de partida para futuras investigaciones académicas.

\section{REFERENCIAS BIBLIOGRÁFICAS}

Burton, Y. (1934). Turkish Door Furnishings. Ars Islamica, 1(2), 223-229. https://www.jstor.org/stable/4515479

Carrasco, P. (1991). La transformación de la cultura indígena durante la Colonia. En B. García, P. Carrasco, P. Gerhard, K. Gosner, D. Dehouve, N. Farriss, R. Knowlton, D. Fraser, M. A. Hersy y M. Velázquez (Eds.), Los pueblos de indios y las comunidades (pp. 1-29). Colegio de México.

Carreras, C. y Nadal, J. (2002). Reflexiones en torno a la cultura material. Nuevas aproximaciones. PYRENAE, (33-34), 65-80. http://diposit.ub.edu/dspace/bitstream/2445/24030/1/520310.pdf

Casiodoro de Reinay Cipriano de Valera. (1960). Biblia. https://www.biblegateway.com/passage/?search=Juan\%20 10\%3A9\&version=RVR1960

Chevalier, J. y Gheerbrant, A. (2007). Diccionario de los simbolos. Herder Editorial.

Cieza, P. (2005). Crónica del Perú. El señorío de los Incas. Biblioteca Ayacucho.

Colomina, P., Lomillos, G. y De Espés, C. (1983). Llamadores faliformes en Ribagorza. Temas de antropología aragonesa, 1(1), 51-62. https://dialnet.unirioja.es/servlet/articulo?codigo $=2917955$

Contreras, F. (1984). Clasificación y tipología en Arqueología. El camino hacia la cuantificación. Cuadernos de Prehistoria de la Universidad de Granada, (9), 327-385. https://revistaseug.ugr.es/index.php/cpag/article/view $/ 1240$

Cornejo, J. (1958). Arte Cuzqueño VI. Revista del Archivo Histórico del Cuzco, (9), 345-419. https://ira.pucp.edu.pe /wp-content/uploads/2020/06/Revista_archivo_cusco.pdf

Cox, P. (1966). Hierro y plata en la Colonia. Artes De México, 1(83), 12-14. http://www.jstor.org.ezproxy.sibdi.ucr. ac.cr:2048/stable/24312660

De Amesti, J. (1982). La forja artística en las Encartaciones (Valle de Muskiz, Valle de Sopuerta, Valle de Galdames y Villa de Valmaseda): S. XVI-XIX. Cuadernos de Sección. Artes Plásticas y Monumentales, 1(1), 39-148. http://w ww.euskomedia.org/PDFAnlt/arte/02/02063184.pdf

Domínguez, F. (1987). Regulación municipal del trabajo libre de los oficios mecánicos en Hispanoamérica colonial. Revista de Historia de América, 1(103), 75-106. http://www.jstor.org.ezproxy.sibdi.ucr.ac.cr:2048/stable/2013 9605

Durand, J., Grijalva, M., Zavala, S., Boyd-Bowman, P., Assadourian, C., Bakewell, P. y García, G. (1992). El ambiente social de la conquista y sus proyecciones en la Colonia. En M. Grijalva (Comp.), La formación de América Latina: La época colonial (pp. 44-62). Colegio de México.

García, L. (1966). El arte del hierro forjado. Artes De México, (83), 11-12. http://www.jstor.org.ezproxy.sibdi.ucr.ac .cr:2048/stable/24312659

Hoffeld, J. M. (1969). The Art of the Medieval Blacksmith. The Metropolitan Museum of Art Bulletin, New Series, 28(4), 161-173. https://www.jstor.org/stable/3258472

Hostnig, R. (2010). Los Herrajes de forja y fundición artística en los portones y puertas del Cuzco colonial y republicano. Boletin de Lima, 1(160), 1-23. https://www.researchgate.net/publication/263698365_Los_herra jes_de_forja_y_fundicion_artistica_en_los_portones_y_puertas_del_Cuzco_colonial_y_republicano

Konetzke, R. (1949). Las ordenanzas de gremios como documentos para la historia social de Hispanoamérica durante la época colonial. Estudios de Historia Social de España, 1(18), 483-524. https://www.econbiz.de/Record/las-ordenanzas-de-gremios-como-documentos-para-la-historia-soci al-de-hispanoamérica-durante-la-época-colonial-konetzke-richard/10002229463

Koselleck, R. (2004). Historia de los conceptos y conceptos de historia. Ayer, 1(53), 27-45. http://www.jstor.org/st able/41325249

Langland, T. (1999). From Clay to Bronze: a Studio Guide to Figurative Sculpture. Watson-Guptill Publications. 
M. Sc. José María Castro Madriz. Tipología del herraje artístico y puerta en Cuzco, Arequipa, La A...

Lechtman, H. (2007). The Inka and the Andean Metallurgical Tradition, Variations in the Expression of Inka Power. Dumbarton Oaks.

Mollet, J. (2002). Diccionario de Arte y Arqueología. Edimat Libros.

Moreyra, C. (2012). Mestizaje, vida cotidiana y cultura material. Una mirada sociocultural a dos matrimonios interétnicos en la ciudad de Córdoba, siglo XVIII. Diálogos Revista Electrónica de Historia, 13(2), 92-111. http: //www.scielo.sa.cr/scielo.php?script=sci_arttext\&pid=S1409-469X2012000200004\&lng=en\&tlng=es

Muro, L. (1956). Herreros y cerrajeros en la Nueva España. Historia Mexicana, 5(3), 337-372. http://www.jstor.org .ezproxy.sibdi.ucr.ac.cr:2048/stable/25134440

Nieto, J. A. (2018). Gremios artesanos, castas y migraciones en cuatro ciudades coloniales de Latinoamérica. Historia y sociedad, (35), 171-197. http://mr.crossref.org/iPage?doi=10.15446\%2Fhys.n35.70215

Palacios, M. (1980). La fragmentación regional de las clases dominantes en Colombia: una perspectiva histórica. Revista Mexicana de Sociologia, 42(4), 1663-1689. https://www.jstor.org/stable/3539965

Real Academia Española. (2020). Aldaba. En Diccionario de la Real Academia Española DRAE. https://dle.rae.es/al daba?m=form

Reyneri, C. (2006). Decoración en hierro: Un recorrido a través de las épocas y los estilos. De Vecchi.

Ruiz, J. (2005). Cultura material y sociedad colonial: Un estudio desde documentos notariales. Santiago 1690-1750 [Tesis de Licenciatura, Universidad de Chile]. http://repositorio.uchile.cl/bitstream/handle/2250/110297/Cultura-material-y-sociedad-colonial-unestudio-desde-documentos-notariales-Santiago-1690-1750.pdf?sequence=4\&isAllowed $=\mathrm{y}$

Salas, M. (2004). Trabajo y salario en los obrajes del Perú colonial a través de sus fuentes, siglo XVI. América Latina en la Historia Económica, (22), 77-104. http://alhe.mora.edu.mx/index.php/ALHE/article/view/343

Sobrino, M.A. (1997). Fray Toribio de Benavente, Motolinía, Memoriales. Nueva Revista De Filología Hispánica (NRFH), 45(2), 493-498. https://doi.org/10.24201/nrfh.v45i2.2015

Tessier, C. (2016). La iconografía andina prehispánica: miradas desde Europa. Recepción, estudio, lectura. Revista de Critica Literaria Latinoamericana, 84(2016), 25-38.

Tschauner, H. (1985). La tipología: ¿ herramienta u obstáculo? la clasificación de artefactos en arqueología. Boletín De Antropología Americana, (12), 39-74. http://www.jstor.org/stable/40977108

Uribe, V. (2007). "Iglesia Me Llamo": Church Asylum and the Law in Spain and Colonial Spanish America. Comparative Studies in Society and History, 49(2), 446-472. http://www.jstor.org.ezproxy.sibdi.ucr.ac.cr:2048 /stable/27563643

Velasco, M. (2016, septiembre). La casa virreinal limeña. En F. Sandoval y J. Sáinz (Coord.), Arquitectura en tierra. Historia y Renovación [Congreso Internacional de Arquitectura de tierra en Cuenca y Villagarcía de Campos] (pp. 81-86). Universidad de Valladolid, España. https://www5.uva.es/grupotierra/publicaciones/digital/libro2 017/07XIIICIATTI2016_Velasco.pdf

Wheat, J., Gifford, J. y Wasley, W. (1958). Ceramic Variety, Type Cluster, and Ceramic System in Southwestern Pottery Analysis. American Antiquity, 24(1), 34-47. http://dx.doi.org/10.2307/276739t

\section{Notas}

1 Gremios establecidos por ordenanzas y regulados por cartas de examen.

2 Véanse el Discurso de la honra y deshonra legal (1791) del doctor Antonio Javier Pérez y López y, de años atrás, El noble bien educado (1776) de Antonio Vila y Camps (Durand et al., 1992, p. 57). Según el Cabildo 9 de julio 1537 de Quito, el platero que hay en la ciudad no la puede abandonar So graves penas. Igualmente, el Cabildo de Santiago de 31 de enero de 1553 prohíbe al herrero abandonar la ciudad (Domínguez, 1987, p. 103). Una de las cartas de cabildo más detalladas con relación a la regulación de precios, oficios, exámenes y penas por infracción es la de Guatemala de 1559. Se fundamenta en el Acta de Cabildo para los herreros del 12 de diciembre de 1524 (Domínguez, 1987, p. 87). https://dle.rae.es/aldaba?m=form. Ahora bien, sobre la representación de la vestimenta indígena, nótese la construcción imaginaria de los artesanos en contraste con los grabados de artistas viajeros y frailes de misiones. Es importante señalar 
que durante los siglos XVII y XVIII, con el desarrollo de los gabinetes de curiosidades y coleccionistas de rarezas, se construyó un exotismo que desemboca en una visión romántica del Nuevo Mundo (Tessier, 2016, p. 27). "Parte de la vivienda que sigue a la portada y conecta la calle con el patio principal (...) se trata de un espacio de transición cubierto, con bancos laterales para la espera y argollas para amarrar las cabalgaduras y que suele ir adornado de arcos y rejas" (Velasco, 2016, p. 84).

3 Según el Cabildo 9 de julio 1537 de Quito, el platero que hay en la ciudad no la puede abandonar So graves penas. Igualmente, el Cabildo de Santiago de 31 de enero de 1553 prohíbe al herrero abandonar la ciudad (Domínguez, 1987, p. 103).

4 Una de las cartas de cabildo más detalladas con relación a la regulación de precios, oficios, exámenes y penas por infracción es la de Guatemala de 1559. Se fundamenta en el Acta de Cabildo para los herreros del 12 de diciembre de 1524 (Domínguez, 1987, p. 87).

5 https://dle.rae.es/aldaba?m=form

6 Ahora bien, sobre la representación de la vestimenta indígena, nótese la construcción imaginaria de los artesanos en contraste con los grabados de artistas viajeros y frailes de misiones. Es importante señalar que durante los siglos XVII y XVIII, con el desarrollo de los gabinetes de curiosidades y coleccionistas de rarezas, se construyó un exotismo que desemboca en una visión romántica del Nuevo Mundo (Tessier, 2016, p. 27).

7 "Parte de la vivienda que sigue a la portada y conecta la calle con el patio principal (...) se trata de un espacio de transición cubierto, con bancos laterales para la espera y argollas para amarrar las cabalgaduras y que suele ir adornado de arcos y rejas" (Velasco, 2016, p. 84). 